CASE REPORT

\title{
Neonatal diabetes mellitus with hypergalactosemia
}

\author{
H Kentrup, J Altmüller, R Pfäfle and G Heimann \\ Department of Pediatrics, University Hospital, RWTH Aachen, Germany \\ (Correspondence should be addressed to H Kentrup, Kinderklinik des Universitätsklinikums der RWTH Aachen, Pauwelsstraße 30, D-52074 Aachen, \\ Germany; Email: hkentrup@t-online.de)
}

\begin{abstract}
We report the case of a male, small-for-gestational-age newborn who presented with failure to thrive, severe fluctuation of blood glucose concentrations, and increased serum concentrations of galactose. The infant responded well to a lactose-free diet supplemented with fructose, inulin and corn starch. The metabolic disorder disappeared within 6 months. The transient course, and results of a molecular analysis of the glucose transporter 2 (Glut2) gene seem to rule out Fanconi-Bickel syndrome.
\end{abstract}

European Journal of Endocrinology 141 379-381

\section{Introduction}

An impaired glucose tolerance in a newborn can be due to a neonatal diabetes mellitus, which may have a transient character (1). An increased serum concentration of galactose in a newborn occurs in classical galactosemia and deficiency of galactokinase. The combination of both an impaired glucose tolerance and a hypergalactosemia may be due to a defect of the facilitative glucose transporter 2 (Glut2), which is the underlying cause of Fanconi-Bickel syndrome (2).

Here we describe such a situation in a newborn, in whom, however, the transient course and the molecular analysis of the Glut2 gene seem to rule out FanconiBickel syndrome. To date, no case of a transient neonatal diabetes mellitus with hypergalactosemia has been described.

\section{Patient report}

A full-term male neonate was admitted for dystrophy immediately after birth. The pregnancy of the firstgravid 34-year-old mother had been complicated by oligohydramnion and fetal retardation, which had been observed sonographically in the last trimester. The newborn had been delivered by cesarean section because of a pathological cardiotocogram. His weight was $1.93 \mathrm{~kg}$ (less than 5 th percentile) his length $44 \mathrm{~cm}$. He had little subcutaneous fat, but otherwise was healthy, without any dysmorphic features.

The initial blood investigation showed a blood glucose concentration of $7.7 \mathrm{mmol} / \mathrm{l}$. The child was entirely breast-fed. On the fifth day, he passed pale stools. Simultaneously, an increase in $\gamma$-glutamyltransferase (199 U/l) and total bilirubin $(66 \mu \mathrm{mol} / \mathrm{l})$ were noted; the proportion of direct bilirubin was $42 \mu \mathrm{mol} / \mathrm{l}$. Blood glucose concentrations increased to $13.4 \mathrm{mmol} / \mathrm{l}$. There were normal values of aspartate aminotransferase, alanine aminotransferase, lactate dehydrogenase, thyroxine and thyrotropin, and of $\alpha$-antitrypsin and sweat chloride concentration.

An abdominal ultrasound scan showed normal liver, pancreas and kidneys without signs of cholestasis.

During the following days, severe fluctuations of blood glucose values were particularly striking. The postprandial values increased by up to $20 \mathrm{mmol} / \mathrm{l}$; before meals, values decreased to less than $2 \mathrm{mmol} / \mathrm{l}$, with concomitant adequate low values of insulin $(2.4 \mu \mathrm{IU} / \mathrm{ml})$. There was no detectable ketonuria. Surprisingly, the serum concentration of galactose was markedly increased, to $1030 \mu \mathrm{mol} / \mathrm{l}$ (normal value $<240 \mu \mathrm{mol} / \mathrm{l}$ ) on the 8th day of life and to $6235 \mu \mathrm{mol} / \mathrm{l}$ 1 day later. Urine analysis revealed both a glycosuria $(10.2 \mathrm{mmol} / \mathrm{l})$ and a galactosuria $(18100 \mathrm{mmol} / \mathrm{l})$. Neonatal metabolic screening, including testing for galactosemia, conducted on day 6 after adequate breast feeding (6×30-40 ml/day) had, however, been negative. Enzyme activities of galactose-1-phosphate uridyltransferase, galactokinase, and UDP-galactose epimerase analyzed thereafter were normal, also. The serum concentrations of total alkaline phosphatase and bone phosphatase were slightly increased, whereas blood values of calcium, phosphorous, and 25-hydroxycholecalciferol were normal. The renal excretion of hydroxyproline was in the upper range of normal. The urine concentrations of calcium and phosphorous were normal in relation to creatinine.

As the child clinically showed polydipsia and failure to thrive, breast feeding was discontinued on day 9 and 
the diet was changed to a galactose-free formula. The clinical condition of the boy finally stabilized after he received a carbohydrate-free formula, which was supplemented, according to blood glucose concentrations and weight gain, with corn starch (finally $1.5 \mathrm{~g} /$ $100 \mathrm{ml}$ ), inulin (finally $3 \mathrm{~g} / 100 \mathrm{ml}$ ), and fructose (finally $4 \mathrm{~g} / 100 \mathrm{ml}$ ). Insulin treatment had not been started initially because of the severe fluctuations in blood glucose; it was not required later on.

Because a defect in glucose-galactose transport was assumed, a molecular analysis of the Glut2 gene was conducted in our own laboratory. All 11 coding exons were amplified by PCR. Intronic primers were chosen so that PCR fragments included all intron-splice sites. The PCR fragments were analyzed by a modified singlestranded conformational analysis (SSCP) according to the method of Orita et al. (3), using silver staining for visualization of the DNA strands (4), and by direct DNA sequence determination (5). By this procedure, all known and presumed novel small mutations within the coding region and the exon-intron boundaries of the Glut 2 gene could be excluded.

During follow-up over the first 6 months of life, blood glucose concentrations normalized and glycosuria disappeared. In the sixth month, solid food in the form of vegetables was added to the diet. In the seventh month, the special diet was stopped completely and subsequently the child was fed with commercially available formulae based on cow's milk; the blood glucose and galactose remained in the normal ranges, and no glycosuria could be detected. The infant appeared normal on the last clinical examination at the age of 7 months with a weight of $7.9 \mathrm{~kg}$, a length of $65.4 \mathrm{~cm}$ and a head circumference of $45.1 \mathrm{~cm}$.

\section{Discussion}

Transient neonatal diabetes mellitus (TNDM) is a rare condition that occurs typically in small-for-date infants and may last for weeks or months, requiring insulin therapy and close monitoring of blood glucose $(1,6)$. The course of neonatal diabetes mellitus is highly variable, and may be either permanent or transient with later recurrence in a small proportion of these cases. The presence of islet-cell antibodies has not been reported in neonatal diabetes mellitus. The permanent form has been described as being associated with multiple epiphyseal dysplasia and renal impairment (Wolcott-Rallison syndrome) $(7,8)$, or with hyperuricemia as a result of phosphoribosyl-ATP pyrophosphatase hyperactivity (1). An association with hypergalactosemia, as found in the case presented, has not been described to date.

The combination of both hyperglycemia and hypergalactosemia is the leading sign of Fanconi-Bickel syndrome, a rare autosomal-recessive metabolic disorder characterized by hepatorenal glycogen accumulation, Fanconi nephropathy and impaired utilization of glucose and galactose, caused by a defect in the facilitative Glut2 gene $(2,9)$. This glucose transporter is expressed in hepatocytes, pancreatic beta-cells, and the basolateral membranes of intestinal and renal epithelial cells (10). It mediates the gradient-dependent bidirectional transport of glucose and galactose through cell membranes. In the hepatocyte, this mechanism is responsible for the smoothing of blood glucose fluctuations. In the pancreatic beta-cell, glucose sensing is dependent on Glut2 function (11). Thus, a defect of Glut2 results in hypergalactosemia and severe fluctuations in blood glucose concentrations.

The Glut2 gene is localized on chromosome 3 (3q26.1-q26.3), and its structure consists of 11 exons and 10 introns spanning approximately $30 \mathrm{~kb}(12)$. To date, four dysfunctional mutations in the human Glut2 gene are known. The first (VAL197ILE) was discovered in a patient with noninsulin-dependent diabetes mellitus $(13,14)$. Santer et al. (2) described a single-base deletion (1BP DEL, 446-449T) and two different nonsense mutations (ARG 365TER, ARG301TER) in patients with Fanconi-Bickel syndrome.

In the infant we have described, there were no signs of Fanconi nephropathy, such as aminoaciduria or phosphaturia; however, this does not exclude FanconiBickel syndrome as a diagnosis, as renal tubular dysfunction may develop later as a consequence of accumulation of glycogen in the proximal tubule (15). However, the pale stools and jaundice were not consistent with Fanconi-Bickel syndrome, and were more likely due to temporary liver dysfunction, for which no reason could be found.

The good response of the infant to a formula in which lactose was substituted by complex carbohydrates, fructose, and inulin differs from other courses of neonatal diabetes mellitus, which have been described as being insulin-dependent (16). Furthermore, it gives evidence that the pathophysiology of this disorder may include a common cause for both the glucose and the galactose utilization defects. The transient character of the disorder, however, indicated that a structural defect of Glut2 was unlikely, and this was underlined by the molecular analysis of the Glut2 gene. However, a delayed expression or differentiation of Glut2 within the various organs could be responsible for this transient disorder.

\section{References}

1 von Muhlendahl KE \& Herkenhoff H. Long-term course of neonatal diabetes. New England Journal of Medicine 1995333 704-708.

2 Santer R, Schneppenheim R, Dombrowski A, Gotze H, Steinmann B \& Schaub J. Mutations in GLUT2, the gene for the liver-type glucose transporter, in patients with Fanconi-Bickel syndrome [published erratum in Nature Genetics 199818 298]. Nature Genetics 199717 324-326.

3 Orita M, Iwahana H, Kanazawa H, Hayashi K \& Sekiya T. Detection of polymorphisms of human DNA by gel electrophoresis 
as single-strand conformation polymorphisms. Proceedings of the National Academy of Sciences of the USA 1989862766 2770 .

4 Bassam BJ, Caetano-Anolles G \& Gresshoff PM. Fast and sensitive silver staining of DNA in polyacrylamide gels. Analytical Biochemistry $199119680-83$.

5 Rosenthal A \& Charnock-Jones DS. New protocols for DNA sequencing with dye terminators. DNA Sequence 19923 61-64.

6 Fosel S. Transient and permanent neonatal diabetes. European Journal of Pediatrics 1995154 944-948.

7 Wolcott CD \& Rallison ML. Infancy-onset diabetes mellitus and multiple epiphyseal dysplasia. Journal of Pediatrics 197280292 297.

8 Stoss H, Pesch HJ, Pontz B, Otten A \& Spranger J. WolcottRallison syndrome: diabetes mellitus and spondyloepiphysea dysplasia. European Journal of Pediatrics 1982138 120-129.

9 Santer R, Schneppenheim R, Suter D, Schaub J \& Steinmann B. Fanconi-Bickel syndrome - the original patient and his natura history, historical steps leading to the primary defect, and a review of the literature. European Journal of Pediatrics $1998157783-$ 797.

10 Mueckler M. Facilitative glucose transporters. European Journal of Biochemistry $1994219713-725$.
11 Bell GI, Kayano T, Buse JB, Burant CF, Takeda J, Lin D et al. Molecular biology of mammalian glucose transporters. Diabetes Care 199013 198-208.

12 Takeda J, Kayano T, Fukomoto H \& Bell GI. Organization of the human GLUT2 (pancreatic beta-cell and hepatocyte) glucose transporter gene. Diabetes 199342 773-777.

13 Tanizawa Y, Riggs AC, Chiu KC, Janssen RC, Bell DS, Go RP et al. Variability of the pancreatic islet beta cell/liver (GLUT 2) glucose transporter gene in NIDDM patients. Diabetologia $199437420-$ 427.

14 Mueckler M, Kruse M, Strube M, Riggs AC, Chiu KC \& Permutt MA. A mutation in the Glut 2 glucose transporter gene of a diabetic patient abolishes transport activity. Journal of Biological Chemistry 1994269 17765-17767.

15 Manz F, Bickel H, Brodehl J, Feist D, Gellissen K, Gescholl-Bauer B et al. Fanconi-Bickel syndrome. Pediatric Nephrology 19871 509-518.

16 Armentrout D. Neonatal diabetes mellitus. Journal of Pediatrics Health Care $1995975-78$.

Received 28 December 1998

Accepted 24 June 1999 